\title{
A Study of the Fire Performance of Electrical Cables
}

\author{
A. C. FERNANDEZ-PELLO \\ Department of Mechanical Engineering \\ University of California at Berkeley \\ Berkeley, California 94720 , USA
}

H. K. HASEGAWA, K. STAGgS, A. E. LIPSKA-QUINN and N. J. ALVARES*

Lawrence Livermore National Laboratory

Livermore, California 94550, USA

\section{ABSTRACT}

Experimental results are presented of the piloted ignition delay time and the upward flame-spread rate over the surfaces of insulated electrical cables under an externally applied radiant flux. The objective of the experiments was to assess and rank the fire performance of seven types of complex cables commonly used in electrical installations. The experiments were carried out with $46 \mathrm{~cm}$ long single cables that were suspended vertically and exposed to irradiance levels ranging from $0.5-2.5 \mathrm{~W} / \mathrm{cm}^{2}$. Some of the cables had a conducting core, and some did not. A simplified analysis, similar to that developed by Quintiere and coworkers was developed to indentify the parameters that dominate the fire characteristics of the cable. A method similar to that proposed by the above authors was applied to develop flammability diagrams and to define the flame spread properties of the cable materials in an attempt to assess and rank the fire performance of the seven types of cable. It is shown that the method can be successfully applied and that it provides a simple way to rank the cables and to calculate the parameters important to ignition and flame spread in electrical cables. The study also explores the feasibility of predicting the piloted ignition performance of the cable insulations using thermogravimetric analysis (TGA) data in conjunction with the ignition and flame spread formulas by proposing that the surface temperature at which thermal degradation produces pryolyzate is related to the ignition temperature for that particular material. The predicted ignition delay times are compared with experimental results and it is shown that for most polymers, the temperature at which thermal degradation is first observed can be used to estimate ignition delay times, particularly at high irradiance levels.

\section{INTRODUCTION}

In installations that contain electronic equipment, plastic or elastomeric cable jackets, and insulations are potential fire sources. Interest in predicting fire behavior of these materials encouraged research aimed at assessing their fire risk [1-7]. Indeed, current industrial standards generally rate cable flammability relative to the performance of some reference material exposed to a specific fire source. Study of the fire performance of electrical cables is complicated because of the nonuniform composition of insulation materials, interaction between the conducting core and insulating jacket, and interaction between cables arranged in complex cable distribution systems. For this reason, most work performed to date has concentrated on determining the overall burning characteristics of specific electrical conductors using pre-established test methods [1-7]. Because of the wide application of electrical conductors, no universal test method is available that can accurately classify the hazardous characteristics of cables under a variety of environmental conditions. This is especially true

\footnotetext{
* Presently at Fire Science Applications, San Carlos, CA
} 
for materials designed for covering the insulation of complex conductors and power cables.

The fire performance of different materials in an actual fire can be determined by measuring various parameters, such as the onset of thermal degradation of the material, the time response of the material to heat, the time response to piloted ignition, the rate of flame spread, and the rate of heat release, using currently standardized test procedures or controlled experiments. Ranking based on listings of these parameters can provide useful information, but often does not lead to general conclusions about the material's performance. This problem can be partially resolved by providing additional information based on fundamental properties of the material as related to its fire performance. Such information could be obtained with basic experiments that provide data of key parameters related to the ignition and flame spread characteristics of the material. The final ranking of the cable would have to be based on all the information available about its flammability characteristics in conjunction with its specific applications. In the present work, we have applied some of the above outlined methodology in an attempt to determine the fire performance of a series of cables commonly used at Lawrence Livermore National Laboratories (LLNL).

\section{EXPERIMENTS}

The experimental apparatus consists basically of a gas-fired radiant panel, a specimen holder frame where the cables were suspended vertically, a pilot burner positioned at the bottom of the specimen, and a water-cooled sliding metal shutter located between the radiant panel and the specimen to precisely control exposure times. The specimens consist of a single $46 \mathrm{~cm}$ long cable suspended vertically in the frame. Two thermocouples are attached to the midpoint of the cable to monitor the specimen temperature; one on the jacket surface and one embedded through the jacket to the conductor. Each cable type is exposed to irradiance levels ranging from 0.5 to $2.5 \mathrm{~W} / \mathrm{cm}^{2}$ to evaluate the effect of increasing flux on the rate of flame spread and time to ignition. The cables tested and their physical properties are given in Table 1.

Table 1. Physical characteristics of cables $(46 \mathrm{~cm}$ long) tested in small-scale radiant panel tests.

\begin{tabular}{lllllcc}
\hline \multicolumn{1}{c}{ Cable } & \multicolumn{1}{c}{$\begin{array}{c}\text { Jacket } \\
(\% \mathrm{wt})\end{array}$} & $\begin{array}{c}\text { Insulation } \\
(\% \mathrm{wt})\end{array}$ & $\begin{array}{c}\text { Conductor } \\
(\% \mathrm{wt})\end{array}$ & $\begin{array}{c}\text { Cable o.d. } \\
(\mathrm{mm})\end{array}$ & $\begin{array}{c}\text { Total wt } \\
(\mathrm{kg} / \mathrm{m})\end{array}$ & $\begin{array}{c}\text { Jacket } \\
\text { thickness (mm) }\end{array}$ \\
\hline $\begin{array}{l}\text { Rg-214u } \\
\text { coaxial }\end{array}$ & $\begin{array}{l}\text { PVC } \\
(21.4)\end{array}$ & $\begin{array}{l}\text { Polyethylene } \\
(17.9)\end{array}$ & $\begin{array}{l}\text { Copper } \\
(60.7)\end{array}$ & 10.9 & 0.18 & 1.59 \\
$\begin{array}{l}\text { PVC } \\
\text { multiconductor }\end{array}$ & $\begin{array}{l}\text { PVC } \\
(25.5)\end{array}$ & $\begin{array}{l}\text { Polypropylene } \\
(4.1)\end{array}$ & $\begin{array}{l}\text { Copper } \\
(70.4)\end{array}$ & 21.0 & 0.60 & 1.59 \\
$\begin{array}{l}\text { Polyethylene } \\
\text { multiconductor }\end{array}$ & Polyethylene & $\begin{array}{l}\text { Polypropylene } \\
(22.6)\end{array}$ & $\begin{array}{l}\text { Copper } \\
(60.0)\end{array}$ & 22.2 & 0.48 & 2.5 \\
$\begin{array}{l}\text { Rubber power } \\
\text { multiconductor }\end{array}$ & $\begin{array}{l}\text { Neoprene } \\
(35)\end{array}$ & $\begin{array}{l}\text { Rubber } \\
(27)\end{array}$ & $\begin{array}{l}\text { Copper } \\
(38)\end{array}$ & 21.8 & 0.73 & 3.05 \\
$\begin{array}{l}\text { Rubber } \\
\text { (Presto W.C. })\end{array}$ & $\begin{array}{l}\text { Rubber } \\
(22.4)\end{array}$ & None & $\begin{array}{l}\text { Copper } \\
(77.6)\end{array}$ & 21.2 & 1.25 & 3.85 \\
$\begin{array}{l}\text { Diesel loc. } \\
\text { 2/0 cable }\end{array}$ & $\begin{array}{l}\text { EP Rubber } \\
(29)\end{array}$ & None & $\begin{array}{l}\text { Copper } \\
(71)\end{array}$ & 18.8 & 0.85 & 4.37 \\
$\begin{array}{l}\text { Diesel loc. } \\
\text { Hatfield 4/0 }\end{array}$ & $\begin{array}{l}\text { Hypalon/rubber } \\
(24)\end{array}$ & None & $\begin{array}{l}\text { Copper } \\
(76)\end{array}$ & 23 & 1.37 & 3.97 \\
\hline
\end{tabular}


The experimental procedure is as follows: Prior to each test, the radiant panel is set to its operating temperature (monitored by a radiation pyrometer) and allowed to stabilize for 30 minutes. Then the shutter is moved in front of the radiant panel and the specimen is hung in place. The shutter is then quickly removed and all monitoring systems are started. Each specimen is preheated until the bulk jacket temperature reaches $100^{\circ} \mathrm{C}$, at which point a 30 $\mathrm{mm}$ acetyline/air pilot flame is applied at the bottom of the jacket. Time to ignition, or flame attachment, and flame spread rate are monitored visually. The test is terminated when the flame has spread up the entire cable, or when it becomes clear that the flame will no longer propagate. Some aspects of this test procedure, in particular the preheating times, were established to duplicate the conditions in large-scale vertical panel tests conducted previously at LLNL [4]. In this procedure the pilot flame used for ignition is in contact with the cable jacket from the time that the surface reaches $100^{\circ} \mathrm{C}$ until ignition is observed. During this period, the pilot flame is contributing to the jacket heating process, and consequently, this additional effect must be considered when analyzing the ignition data.

Accurate determination of the pilot flame contribution is difficult to make because in the present tests, the flame was in actual contact with the jacket and it is difficult to simulate the actual conditions using a radiometer or calorimeter. Measurement of the pilot flame heat flux made with a radiometer for distances up to $25 \mathrm{~mm}$ and with a calorimeter up to the point of flame contact showed that the value that appeared to be the most representative of the pilot flame contribution was approximately $2.5 \mathrm{~W} / \mathrm{cm}^{2}$. Since this value was in agreement with the one that could be deduced from the ignition time and flame spread data, it was selected in this work as that representing the pilot flame contribution to the cable jacket heating during the ignition period. It should be noted that a similar level of flame-contributed heat flux is defined for the pilot ignition source of the Ohio State Heat release rate calorimeter.

The $100^{\circ} \mathrm{C}$ preheat time for cable jackets at different values of external irradiance was used to calculate with Eq. (1) the $\mathrm{kpc}$ value of the different cables. The resulting $\mathrm{kpc}$ values are included in Table 2. The two different values of kpc obtained, corresponding to small and large irradiance levels, appear to be the effect of the conducting core on the cable heating process. At low radiant levels, the solid heating process is slow and can penetrate up to the metallic cable core. The contribution from the larger heat capacity and thermal conductivity of the metal core results in a large value of kpc. For high irradiance levels, the exposure time is small and the heat penetration depth is limited to the cable jacket, which results in a small value of $\mathrm{kpc}$.

Figure 1 shows measurements of the time to pilot ignition and the upward spread of the flame along the jacket surface of a Prestoflex 40 cable at different levels of irradiance. For these data, the cable jackets are radiantly heated to a bulk temperature of $100^{\circ} \mathrm{C}$ before the pilot flame is applied. The recorded ignition delay is the time between pilot flame application and cable jacket ignition. Ignition is considered to occur when flame attachment is observed. Experimental data similar to that presented in the figure 1 obtained for the different cables tested was used to produce the ignition curves in figure 2 . These data result from at least two tests and are accurate to $\pm 20 \%$. The contribution from the pilot flame has already been incorporated in the preparation of this figure. Thus, the curves presented are those deduced from the raw data displaced toward the right $2.5 \mathrm{~W} / \mathrm{cm}^{2}$ to account for the pilot flame heat flux which acts also as an external heat source and consequently must be added to the heat flux from the radiant panel. The data from figure 1 and the similar ones for the other cables are also used to calculate the rate of flame spread. Figure 1 shows that there is a minimum irradiance for flame spread to occur. Also it is observed that the flame spread rate is faster near the base of the cable than at its upper portion. This last trend is most likely due to a combination of two effects; the heat transferred from the pilot flame to the cable surface that enhance the spread of the flame in the lower region of the cable, and the thermal burnout of the bottom cable material which affects the pyrolysis and the flame lengths and consequently determines the ultimate flame spread rate. The variation of the upward flame spread rate with the external irradiance is presented in figure 3 for the cables tested. The flame spread rate data are averaged values of the flame spread from measurements of the 


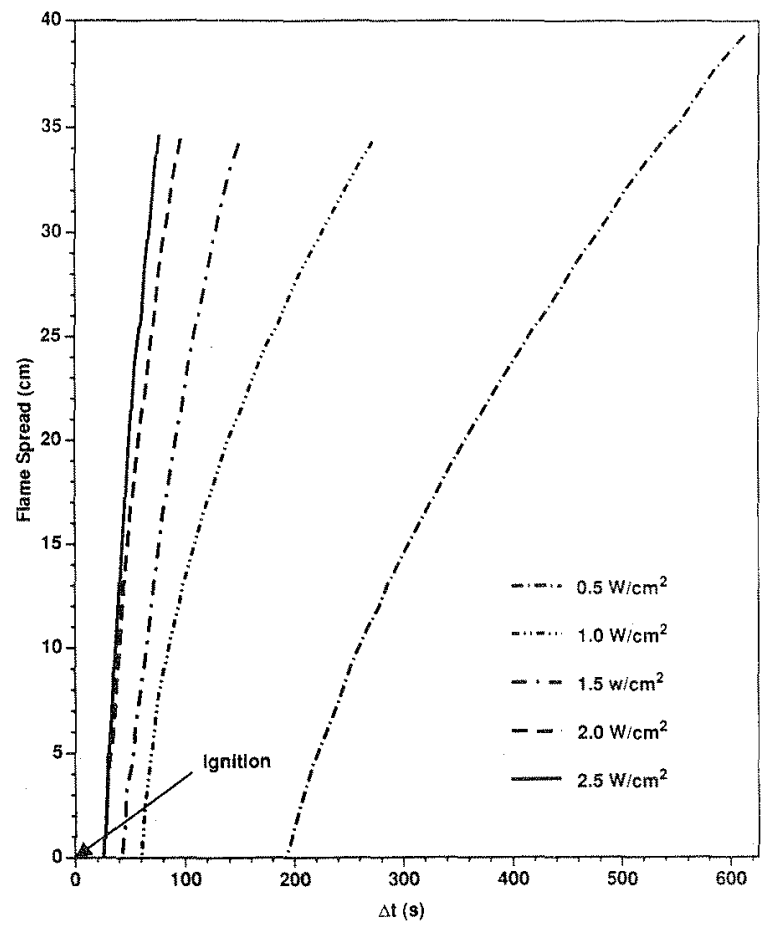

Fig. 1. Time to pilot ignition and length of flame spread along the jacket surface of a Prestoflex 410 cable at different irradiance levels.

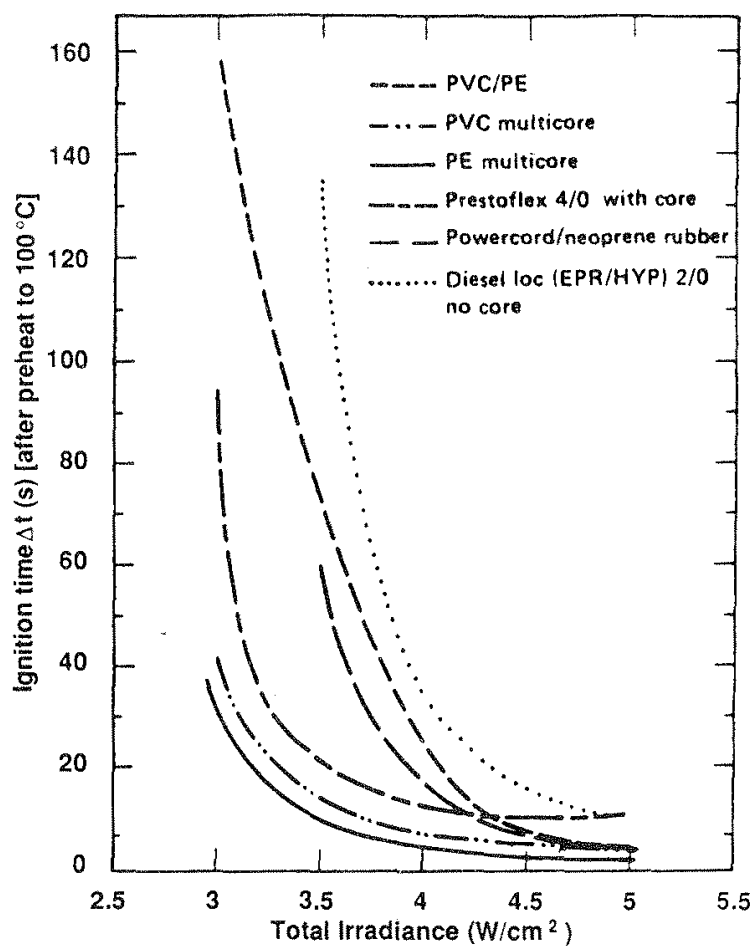


upward progress of the flame, and are accurate to $\pm 20 \%$. The irradiance values for these data do not include contribution from the pilot since the pilot is active only during ignition and its effect is limited to only the bottom surface of the cable jacket.

The data in figures 2 and 3 can be used to provide information about the fire performance characteristics of the different cables. It is interesting to note that the hazardous ranking according to piloted ignition characteristics (small ignition times) does not necessarily agree with that obtained from flame spread characteristics (large flame spread rate). A possible reason for this is the effect of material charring, or of fuel burnout which is more important in flame spread than in ignition.

\section{THEORETICAL BACKGROUND}

In this section, a simplified theoretical model of the cable heating, ignition and upward flame spread is developed to define the essential features of the cable flammable behavior. The model follows the guidelines established by Quintiere [8] in his analysis of the ignition and lateral spread of flames over flat combustible surfaces, and assumes that the cable behaves as a thermally-thick solid with constant properties. Assuming that the external radiant flux, $\dot{\mathrm{q}}_{\mathrm{e}}$ ", is absorbed at the solid surface, and using a linearized heat transfer coefficient, $h$, that accounts for convection and radiation heat losses, the instantaneous surface temperature of the cable, $T_{s}$, will be given by $[8,9]$

$\mathrm{T}_{\mathrm{s}}=\mathrm{T}_{\mathrm{a}}+\frac{\dot{\mathrm{q}}_{\mathrm{e}}^{\prime \prime}}{\mathrm{h}} \mathrm{F}(\mathrm{t})$

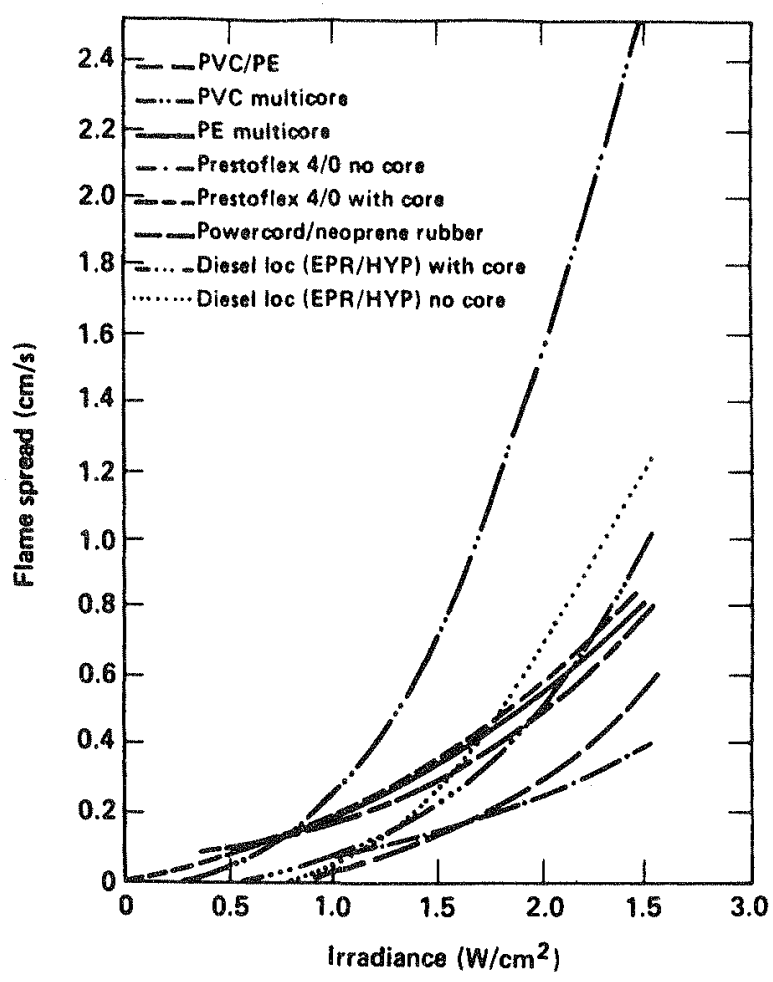

Fig. 3. Rate of upward flame spread as a function of the external irradiance for the different cables tested. 
where $F(t)=2 h(t / \pi k p c)^{1 / 2}$ for small time periods. $F(t)=1$ for large periods of time (i.e., thermal equilibrium). Respectively, $T_{a}, k, \rho$, and $c$ are the initial temperature, thermal conductivity, density and specific heat of the cable.

Piloted ignition of the cable will occur when enough fuel vapor is gasified so that the lean flammability limit is reached near the cable surface. Because the rate of pyrolysis of most materials is very sensitive to the surface temperature of the material, it is possible to approximately relate the onset of ignition to the surface temperature of the material. For given geometrical and gas flow configuration, the temperature at which piloted ignition of the gases near the solid surface occurs is then defined as the ignition temperature. This temperature is probably relatively constant and approximately corresponds to that at which thermal degradation of the material starts to take place. Thus, if the ignition or the thermal degradation temperature is known, Eq. (1) can be used to calculate ignition times as a function of the irradiance at least approximately. of time. The resulting expression is,

$\Delta t_{\mathrm{ig}}=\frac{\pi \mathrm{kpc}\left(\mathrm{T}_{\mathrm{ig}}-\mathrm{T}_{\mathrm{o}}\right)^{2}}{4\left(\dot{\mathrm{q}}_{\mathrm{e}}^{\prime \prime}-\mathrm{h}\left(\mathrm{T}_{\mathrm{ig}}-\mathrm{T}_{\mathrm{a}}\right)\right)^{2}}$

where $T_{i g}$ is the ignition temperature, $T_{o}$ is a reference jacket temperature, $T_{a}$ the ambient temperature, $\mathrm{h}$ incorporates a convective and a linearized radiation heat transfer coefficients, and $\Delta \mathrm{t}_{\mathrm{ig}}$ is the ignition delay time. In the present case, $\mathrm{q}_{\mathrm{e}}{ }^{\prime \prime}$ includes the contribution from the pilot flame, i.e., $2.5 \mathrm{~W} / \mathrm{cm}^{2}$. For low irradiance, or equivalently long heat times, the solid surface may come into thermal equilibrium before the ignition temperature is reached. This condition leads to the determination of the minimum heat flux for solid ignition as

$\dot{\mathrm{q}}^{\prime \prime}{ }_{\mathrm{o}, \mathrm{ig}}=\mathrm{h}\left(\mathrm{T}_{\mathrm{ig}}-\mathrm{T}_{\mathrm{a}}\right)$

Substitution of (3) in (2) gives for the ignition time

$\Delta \mathrm{t}_{\mathrm{ig}}=\frac{\pi \mathrm{kpc}\left(\mathrm{T}_{\mathrm{ig}}-\mathrm{T}_{\mathrm{o}}\right)^{2}}{4\left(\dot{\mathrm{q}}_{\mathrm{e}}^{\prime \prime}-\dot{\mathrm{q}}^{\prime \prime}{ }_{\mathrm{o}, \mathrm{ig}}\right)^{2}}$

The sequence of events leading to the spread of the flame can be compared to those that a solid element, initially at the forward edge of the solid surface heated by the flame, would undergo to its ignition. Since the time for the solid element to ignite is the same as for the flame to propagate to the solid element position, the rate of flame spread will be given by the ratio of the heated length ahead of the pyrolysis front, $l_{\mathrm{f}}$, to the solid ignition time, $\Delta \mathrm{t}_{\mathrm{ig}}$, i.e., $\mathrm{V}_{\mathrm{f}}=l_{\mathrm{f}} / \Delta \mathrm{t}_{\mathrm{ig}}$. From Eq. (2), the following expression is obtained for the upward flame spread rate over the cable surface

$\mathrm{V}_{\mathrm{f}}=\frac{4\left(\dot{\mathrm{q}}_{\mathrm{f}}^{\prime \prime}+\dot{\mathrm{q}}_{\mathrm{e}}^{\prime \prime}-\mathrm{h}\left(\mathrm{T}_{\mathrm{ig}}-\mathrm{T}_{\mathrm{a}}\right)\right)^{2} l_{\mathrm{f}}}{\pi \mathrm{kpc}\left(\mathrm{T}_{\mathrm{ig}}-\mathrm{T}_{\mathrm{o}}\right)^{2}}$

where $\dot{\mathrm{q}}_{\mathrm{f}}^{\prime \prime}$ is the heat flux from the flame to the surface. $\dot{\mathrm{q}}_{\mathrm{e}}$ " is the contribution from the external radiant source, and $l_{\mathrm{f}}$ the flame length. In most cases, it can be assumed that fiame spread occurs under thermal equilibrium conditions. Then the rate of flame spread can be expressed in terms of the critical heat flux for ignition, and the external radiant flux, as [8-10]

$\mathrm{V}_{\mathrm{f}}=\frac{1}{\mathrm{C}^{2}\left(\dot{\mathrm{q}}_{\mathrm{ig}}{ }^{\prime \prime}-\dot{\mathrm{q}}_{\mathrm{e}}{ }^{\prime \prime}\right)^{2}}$ 
where $\mathrm{C}$ is the flame spread rate coefficient.

Equations (4) and (6) show that the critical heat flux for ignition establishes a boundary between the flame spread and the ignition processes. Both the ignition delay time and the flame spread rate tend to infinity when the externally applied heat flux approaches the value of the critical heat flux for ignition. The above analysis shows that the theoretical development for the present experimental setup is similar to that developed by Quintiere et. al. [810] for the lateral flame spread tests. The magnitude of some of the parameters are different because of the geometrical differences between the upward and lateral flame spreads. A major source of difference is the magnitude of the heated region in the solid, $l_{\mathrm{f}}$, which depends on the pyrolysis length, $l_{\mathrm{p}}$, increasing as $l_{\mathrm{p}}$ increases, and is the primary cause for the transient behavior of the upward flame spread [11]. Charring of the material affects the magnitude of the pyrolysis length and consequently of the flame length and, since this effect is strong for cables, it is expected that charring will play a more important role in this case.

\section{FLAMMABILITY DIAGRAMS}

If the experimental data for the variation with the irradiance of the ignition delay time and flame spread rate (figures 2 and 3 ) are plotted in the same graph, the resulting plots can be viewed as flammability diagrams for the material, which provide in conjunction with the theory a useful and interesting approach to deduce the ignition and flame spread parameters of the particular material. Generation of these flammability diagrams was first suggested by Quintiere and coworkers [8-10] who have applied them extensively and very successfully to the determination of the flammability characteristics of a large variety of building materials. A characteristic example of this type of plot to the cables studied here is shown in figure 4 for PVC/PE coaxial cable. It is seen that both the ignition and flame spread curves present a common asymptotic value of the external irradiance of approximately $2.9 \mathrm{~W} / \mathrm{cm}^{2}$. This irradiance corresponds to the critical irradiance for ignition of PVC/PE coaxial cable. This parameter by itself provides an important source of information about the flammability of the material, and could be used to rank the fire behavior characteristics of the cable. It can also be used to calculate averaged values of the flame spread rate coefficient, C, from Eq. (6) in conjunction with the calculated value of $\mathrm{kpc}$ and the measured flame spread rate. For PVC/PE coaxial cable, we deduced that $\mathrm{C}=1.3(\mathrm{~s} / \mathrm{cm})^{1 / 2} \mathrm{~cm}^{2} / \mathrm{W}$. The corresponding theoretical flame spread curve obtained with Eq. (6) is also shown in figure 4.

Another important parameter that characterizes the fire behavior of the material is the ignition temperature, $\mathrm{T}_{\mathrm{ig}}$. The ignition temperature and the critical irradiance for ignition are related by Eq. (3). If the value of the ignition temperature is known, it can be used in Eq. (4) to predict ignition delay times or in Eq. (5) to predict rates of flame spread. The theoretical prediction of the ignition delay time obtained from Eq. (4) is also presented in figure 4. The two branches correspond to the two values of kpc. Agreement between theory and experiments is better at higher irradiance. This is as expected since Eq. (4) is better applicable for short exposure times to external radiations.

Table 2 summarizes the values of the ignition and flame spread properties deduced from the flammability diagrams in conjunction with the theoretical analysis for all the cable tested in this work. The table also includes the ignition delay time at an irradiance of $1 \mathrm{~W} / \mathrm{cm}^{2}$, and the flame spread rate at an irradiance of $2.5 \mathrm{~W} / \mathrm{cm}^{2}$. This last additional information is provided to help rank different cables since, in some cases, the ignition and flame spread parameters are too close to differentiate them. The selection of the irradiance levels at which the ignition time and spread data is obtained is somewhat arbitrary although correspond to average tested values. With regard to information provided in Table 2 concerning fire behavior of the material, a hazardous material is one with a small $\mathrm{kpc}, \dot{\mathrm{q}}_{\mathrm{ig}}{ }^{\prime \prime}, \mathrm{T}_{\mathrm{ig}}, \mathrm{C}, \Delta \mathrm{T}_{\mathrm{ig}}$, and a large $\mathrm{V}_{\mathrm{f}}$. A small $\mathrm{kpc}$ implies a higher heating rate for a given heat flux. A small $\dot{q}_{\text {ig }}$ " or $\mathrm{T}_{\mathrm{ig}}$ will result in small ignition delays or larger flame spread rates for a given heat flux. A small $\mathrm{C}$ implies a larger flame spread rate when the other parameters are identical. 


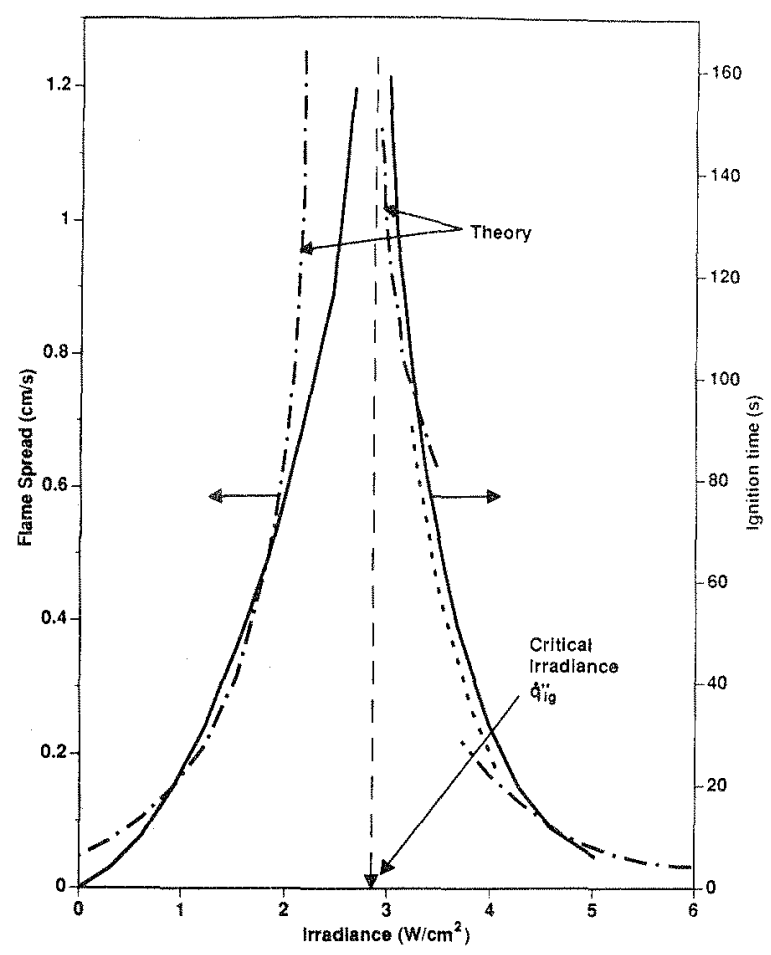

Fig. 4. Flammability diagram for a PVC/PE coaxial cable. Also included are the ignition time and flame spread predictions from Eqs. (3) and (5).

A ranking of the cable according to the ignition parameters does not always agree with the ranking according to the flame spread parameters. As we explained before, we believe that this is due to charring and material depletion effects which effect the flame spread process more than the ignition process. Because of the larger contribution to the development of a fire by the flame spread, we have ranked cables in Table 2 based on the flame spread parameters rather than on the ignition parameters. However, if more importance had been given to the ignition parameters, the resulting cable ranking would have been only slightly different.

\section{THERMAL DEGRADATION DATA AND PREDICTIONS}

The objective of this task is to investigate the use of data from thermogravimetric analysis (TGA) of cable insulation materials to predict the piloted ignition and flame spread characteristics of electrical cables. The work is based on the premise that ignition of a combustible material is preceded by its thermal degradation, and that consequently the temperature for the onset of thermal degradation may define the lowest limit for the materials. Thermogravimetric analysis is a procedure for identifying thermal degradation behavior of materials. In a standard setup, approximately $10 \mathrm{mg}$ of the sample is heated isothermally in a microbalance-supported microfurnace to a predetermined temperature program (typically set in ${ }^{\circ} \mathrm{C} / \mathrm{min}$ ). The TGA output indicates the changes in sample weight as a function of time and temperature. Since all materials ultimately decompose upon heating, and since the decomposition temperature is a characteristic property of each material, this is a universal technique for characterizing and identifying materials. The measurements are made in inert atmospheres (nitrogen is common) or in oxidizing atmospheres, and the maximum heating rate is $160^{\circ} \mathrm{C} / \mathrm{min}$. Heating a sample in air characterizes the effects of oxygen on pyrolysis. Standard TGA practice defines an "onset" temperature by the intersect of a line extrapolated from the zero weight loss region to a line drawn tangent to where the slope of maximum 
Table 2. Ignition, flame-spread parameters and ranking of the cables tested.

\begin{tabular}{|c|c|c|c|c|c|c|c|c|}
\hline Cable & $\begin{array}{c}\mathrm{kpc} \\
\left(\mathrm{W} / \mathrm{cm}^{2} \mathrm{~K}\right)^{2} \mathrm{~S}\end{array}$ & $\begin{array}{c}\dot{q}^{\prime \prime}{ }^{\prime} \\
W / \mathrm{cm}^{2}\end{array}$ & $\begin{array}{c}\mathrm{C} \\
\mathrm{s} \mathrm{cm}^{2 / 5} / \mathrm{W} \\
\end{array}$ & $\begin{array}{l}\Delta \mathrm{t}_{\mathrm{ig}} \\
(\mathrm{s})\end{array}$ & $\begin{array}{c}\mathrm{V}_{\mathrm{f}} \\
(\mathrm{cm} / \mathrm{s})\end{array}$ & $\begin{array}{c}\mathrm{T}_{\text {in }} \\
\left({ }^{\circ} \mathrm{C}\right)\end{array}$ & $\begin{array}{l}\mathrm{T}_{\text {ons }} \\
\left({ }^{\circ} \mathrm{C}\right)\end{array}$ & Rank \\
\hline $\begin{array}{l}\text { PVC/PE } \\
\text { Coaxial RG } 214\end{array}$ & $\begin{array}{l}0.03 \text { low } \\
0.006 \text { high }\end{array}$ & 2.9 & 1.3 & 72 & 0.9 & 280 & 340 & 4 \\
\hline $\begin{array}{l}\text { PVC } \\
\text { Multiconductor }\end{array}$ & $\begin{array}{l}0.01 \\
0.0085\end{array}$ & 2.8 & 1.1 & 10 & 2.6 & 250 & 310 & 1 \\
\hline $\begin{array}{l}\text { PE } \\
\text { Multiconductor }\end{array}$ & $\begin{array}{l}0.016 \\
0.01\end{array}$ & 2.9 & 1.3 & 9 & 0.8 & 270 & 376 & 2 \\
\hline $\begin{array}{l}\text { Prestoflex } 4 / 0 \\
\text { Rubber no core }\end{array}$ & 0.0065 & 3.0 & 1.9 & 30 & 0.4 & 250 & 330 & 7 \\
\hline $\begin{array}{l}\text { Prestoflex } 4 / 0 \\
\text { Rubber with core }\end{array}$ & $\begin{array}{l}0.04 \\
0.009\end{array}$ & 2.9 & 1.4 & 20 & 0.75 & 250 & 330 & 3 \\
\hline $\begin{array}{l}\text { Powercord } \\
\text { Neoprene rubber }\end{array}$ & $\begin{array}{l}0.03 \\
0.0075\end{array}$ & 3.2 & 2.0 & 60 & 0.55 & 300 & 376 & 8 \\
\hline $\begin{array}{l}\text { Diesel loc } 2 / 0 \\
\text { EPR/Hyp with core }\end{array}$ & $\begin{array}{l}0.05 \\
0.009\end{array}$ & 3.3 & 1.3 & 100 & 1.0 & 180 & 306 & 5 \\
\hline $\begin{array}{l}\text { Diesel loc } 2 / 0 \\
\text { EPR/Hyp no core }\end{array}$ & $\begin{array}{l}0.01 \\
0.008\end{array}$ & 3.3 & 1.2 & 135 & 1.2 & 180 & 306 & 6 \\
\hline
\end{tabular}

weight loss begins. Initiation of weight loss is indicated by the point where the weight loss curve separates from the zero weight loss position. This position defines an "initiation" temperature at which thermal degradation commences and pyrolyzate production starts. The measured initiation and onset temperatures of the cables studied in this work are presented in Table 2.

Assuming that either the initiation or the onset temperature of thermal degradation corresponds to the cable's jacket ignition temperature, then Eqs. (2) and (5) can be used to predict respectively the ignition delay times and flame spread rates for a given external irradiance. The predictions can be compared with the results in figures 2 and 4 to verify the potential use of TGA to predict cable fire behavior. Figure 5 presents the resulting ignition diagram for a PVC multiconductor cable together with the experimental data. In the figure, the variation with the external irradiance of the cable's ignition time is shown for the cases when the ignition temperature is taken as the initiation or the onset temperature of thermal degradation.

Figure 5 shows that the cable ignition delay time dependence on the external irradiance is predicted fairly well using the initiation temperature of thermal degradation for high irradiances. The predictions using the onset temperature are poorer. In most cases, the initiation temperature produces a better agreement between theory and experiments, particularly at high irradiance levels. From the ignition and flame spread diagrams of the different cables, it was observed that this procedure works best when applied to materials with formulations that do not contain additives. Composite materials will have thermal decomposition patterns that reflect the physical make up of its components, leading either to indistinct or multiple onset temperatures and a different general decomposition scheme. Nevertheless, for most materials, agreement between predictions and measurement supports use of Eqs. (2) and (5) and thermal degradation data to provide approximate cable ignition and flame spread behavior. Our results also point out that this method is only applicable if the initial degradation products are combustible. Identification of TGA pyrolyzates could be performed to track 


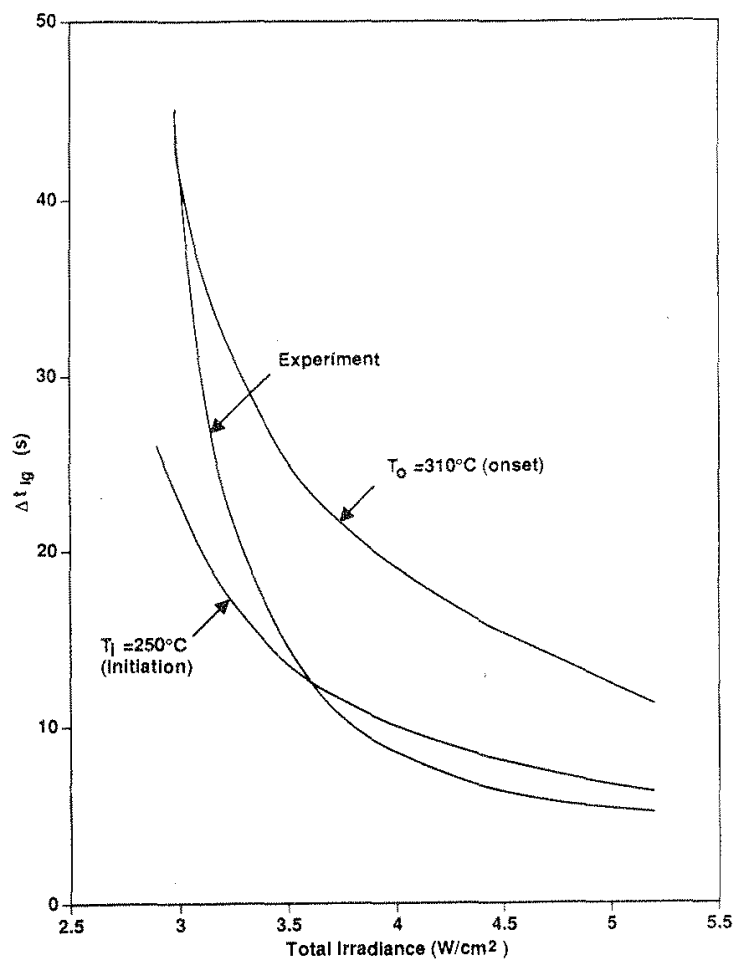

Fig. 5. Comparison of the experimental ignition delay time and the predictions of Eq. (3) using the TGA initiation or onset temperature as a function of the external irradiance for a PVC multiconductor cable.

combustible components. However, this procedure would not be simple and would negate the attributes of TGA. Another aspect of the problem is that in the TGA the material is uniformly heated in an isothermal environment, while in the ignition test, or in practice, the material is heated by externally applied heat flux from a nonuniform radiation source. This can produce a steep temperature distribution in the material layer near the surface that may cause selective gasification of different components of the material.

\section{CONCLUSIONS}

The results of this work also show that the test procedure proposed by Quintiere and co-workers [8-10] provides a simple and systematic way to rank the fire performance of insulated electrical cables. This is particularly significant because of the complexity of the cables tested -- the cables have insulations of different compositions and interactions between the conductor and the insulation affect the fire performance. In addition to providing a procedure to rank the materials, the analysis supporting the procedure also provide simple formulas for the ignition delay and flame spread rate that can be used in fire models to estimate the development of compartment fires containing electrical equipment. The results of this work also indicate that the initiation of thermal degradation obtained from TGAs can be used on a limited basis as an equivalent ignition temperature both as an indicator of the ease of ignition and in simple models of ignition and flame spread to predict the fire behavior of polymeric materials, including cable insulations.

\section{ACKNOWLEDGEMENT}

This work was performed under the auspices of the U.S. Department of Energy by Lawrence Livermore National Laboratory under Contract W-7405-Eng-48. 


\section{REFERENCES}

1. Underwriters Laboratories, UL910 Standard for Test Method for Fire and Smoke Characteristics of Cables Used in Air-Handling Spaces.

2. Newman, J.S. and Hill, J.P., "Assessment of Exposure Fire Hazards to Cable Trays," FMRC, Norwood, MA, EPRI NP-1675, 1981.

3. Dube, D.A., "Fire Protection Research for the US Nuclear Regulatory Commission 1975-1981," Sandia Nat. Labs. Albuquerque, NM, NUREG/CR-2607, 1983.

4. Hasegawa, H.K., Alvares, N.J., Lipska-Quinn, A.E., Beason, K.L., Foote, K.L., Priante, S.J., and Staggs, K.J., "Fire Protection Research for DOE Facilities: FY 84 Year-End Report," LLNL, Livermore, CA, UCRL-53179-84, 1985.

5. Tewarson, A. and Khan, M.M., 22nd Symp. (Int.) Comb., The Comb. Inst., p. 1231, 1988.

6. Sugawa, O. and Handa, T., Fire Saf. Sci., Proc. Second Int. Symp., 781, 1989.

7. Tewarson, A. and Khan, M.M., Fire Saf. Sci., Proc. Second Int. Sym., 781, 1989.

8. Quintiere, J., Fire and Materials, U.S. No. 2, p. 52, 1981.

9. Quintiere, J., Harkleroad, M., and Walton, D., Comb. Sci. and Tech., 32, 67, 1983.

10. Quintiere, J. and Harkleroad, M., "New Concepts for Measuring Flame Spread Properties," NBS Report, NBS(R 86.794), Nov. 1984.

11. Fernandez-Pello, A.C. and Hirano, T., Comb. Sci. and Tech., 32, 1, 1983. 
do 